\title{
Can $\left[\mathrm{M}\left(\mathrm{H}_{2}\right)_{2}\left(\mathrm{H}_{2}\right)(\mathrm{PXP})\right]$ Pincer Complexes $(\mathrm{M}=\mathrm{Fe}, \mathrm{Ru}, \mathrm{Os} ; \mathrm{X}=\mathbf{N}, \mathbf{O}, \mathbf{S})$ Serve as Catalyst Lead Structures for $\mathrm{NH}_{3}$ Synthesis from $\mathrm{N}_{2}$ and $\mathbf{H}_{2}$ ?
}

\author{
Markus Hölscher, Martin H. G. Prechtl, and Walter Leitner*[a]
}

\begin{abstract}
The potential of pincer complexes $\left[\mathrm{M}(\mathrm{H})_{2}\left(\mathrm{H}_{2}\right)(\mathrm{PXP})\right](\mathrm{M}=\mathrm{Fe}, \mathrm{Ru}$, Os; $\mathrm{X}=\mathrm{N}, \mathrm{O}, \mathrm{S})$ to coordinate, activate, and thus catalyze the reaction of $\mathrm{N}_{2}$ with classical or nonclassical hydrogen centers present at the metal center, with the aim of forming $\mathrm{NH}_{3}$ with $\mathrm{H}_{2}$ as the only other reagent, was explored by means of DF (density functional) calculations. Screening of various complexes for their ability to perform initial hydrogen transfer to coordinated $\mathrm{N}_{2}$ showed ruthenium pincer complexes to be more promising than the corresponding iron and osmium analogues. The ligand backbone influences the reaction dramatically: the presence of pyridine and thioether groups as backbones in the ligand result in inactive
\end{abstract}

catalysts, whereas ether groups such as $\gamma$-pyran and furan enable the reaction and result in unprecedented low activation barriers $\left(23.7\right.$ and $22.1 \mathrm{kcal} \mathrm{mol}^{-1}$, respectively), low enough to be interesting for practical application. Catalytic cycles were calculated for $\left[\mathrm{Ru}(\mathrm{H})_{2}\left(\mathrm{H}_{2}\right)(\mathrm{POP})\right]$ catalysts $(\mathrm{POP}=$ 2,5-bis(dimethylphosphanylmethyl)furan and 2,6-bis(dimethylphosphanylmethyl)- $\gamma$-pyran). The height of activation barriers for the furan system is somewhat more advantageous. Forma-

Keywords: activation energy • ammonia $\cdot$ density functional calculations $\cdot$ homogeneous catalysis $\cdot$ pincer complexes $\cdot$ ruthenium tion of inactive metal nitrides has not been observed. SCRF calculations were used to introduce solvent (toluene) effects. The Gibbs free energies of activation of the numerous single reaction steps do not change significantly when solvent is included. The reaction steps associated with the formation of the active catalyst from precursors $\left[\mathrm{M}(\mathrm{H})_{2}\left(\mathrm{H}_{2}\right)(\mathrm{PXP})\right]$ were also calculated. The otherwise inactive pyridine ligand system allows for the generation of the active catalyst species, whereas the ether ligand systems show activation barriers that could prohibit practical application. Consequently the generation of the active catalyst species needs to be addressed in further studies.

\section{Introduction}

Although heterogeneously catalyzed ammonia synthesis has long been known and is well understood, ${ }^{[1]}$ the homogeneously catalyzed synthesis of $\mathrm{NH}_{3}$ from $\mathrm{N}_{2}$ and $\mathrm{H}_{2}$ by a defined transition-metal complex is one of the unresolved challenges in chemistry. ${ }^{[2]}$ Significant efforts, many of them driven by an attempt to understand biological nitrogen reduction, have been made to synthesize and characterize transition-metal complexes that bond with and activate the

[a] Dr. M. Hölscher, Dipl.-Chem. M. H. G. Prechtl, Prof. Dr. W. Leitner Institute of Technical and Macromolecular Chemistry RWTH Aachen, Worringer Weg 1, 52074 Aachen (Germany) Fax: (+49)241-802-2177

E-mail: leitner@itmc.rwth-aachen.de

Supporting information for this article is available on the WWW under http://www.chemeurj.org/ or from the author. It contains Cartesian coordinates and tables with energies as well as graphical representations of most of the structures together with selected structural parameters.
$\mathrm{N}_{2}$ molecule. A wealth of metal complexes (for example, titanium, ${ }^{[3]}$ zirconium, ${ }^{[4,9 c]}$ vanadium, ${ }^{[5]}$ molybdenum, ${ }^{[6]}$ and iron complexes ${ }^{[7]}$ ) were shown to bond with and activate the $\mathrm{N}_{2}$ molecule to varying extents, some of them even breaking the $\mathrm{N}-\mathrm{N}$ structure motif completely. Many of the theoretical and spectroscopic data available have been analyzed. ${ }^{[8]}$ Most of the synthetically derived transition-metal complexes tested for catalytic reduction of $\mathrm{N}_{2}$ to form ammonia proved inactive. However, very stimulating progress has been made recently with regard to both reduction methods $\left(\mathrm{N}_{2} / \mathrm{H}_{2}\right.$ and $\mathrm{N}_{2} / \mathrm{H}^{+} /$reducing agent). For instance, in the former case the complex $\left[\left\{\mathrm{Zr}\left(\eta^{5}-\mathrm{C}_{5} \mathrm{Me}_{4} \mathrm{H}\right)_{2}\right\}_{2}\left(\mu^{2}, \eta^{2}, \eta^{2}-\mathrm{N}_{2}\right)\right]$ with side-onbonded $\mathrm{N}_{2}$ reacted in the presence of $\mathrm{H}_{2}$ to yield $\mathrm{NH}_{3}$. However, the starting complex was consumed, rendering the reaction stoichiometric. ${ }^{[9 a]}$ These experimental results were rationalized on the basis of DFT calculations. ${ }^{[9 b-e]}$

With regard to mimicking the biological process of $\mathrm{N}_{2}$ fixation and reduction to $\mathrm{NH}_{3}$ using protons and reducing agents, in a seminal work by Schrock and co-workers the synthetic complex $\left[\mathrm{Mo}\left(\mathrm{N}_{2}\right)\left(\mathrm{HIPTN} \mathrm{N}_{3} \mathrm{~N}\right)\right]\left(\mathrm{HIPTN}_{3} \mathrm{~N}=\right.$ hexa- 
isopropylterphenyltriamidoamine) proved to be an active catalyst for catalytic $\mathrm{NH}_{3}$ synthesis. ${ }^{[10]}$ In this approach $\mathrm{N}_{2}$ was first coordinated at the molybdenum complex, and subsequently protonated/reduced repeatedly in the presence of acids (proton source) and metallocenes (reducing agent), generating $\mathrm{NH}_{3}$. Meanwhile some intermediates were characterized spectroscopically and crystallographically, while important details of the mechanism were elucidated by computational studies. ${ }^{[11]}$

In a very recent DFT study on molybdenum, ruthenium, and osmium model complexes closely related to the original Schrock catalyst, we investigated the catalytic potential of metal hydrides of general formula $[\mathrm{M}=\mathrm{H}(\operatorname{tren})]$ (tren $=$ tris(2-amidoethyl)amine or tris(2-amidoethyl)phosphane) for $\mathrm{NH}_{3}$ formation using only $\mathrm{N}_{2}$ and $\mathrm{H}_{2} \cdot{ }^{[12]}$ For these complexes with formal oxidation state +4 at the metal center, catalytic cycles could be calculated. For the molybdenum system we found activation barriers that were much too high to consider any experimental approach. We also observed that for the ruthenium and osmium systems some of the many single reaction steps have much lower activation barriers than the molybdenum system; these seem to be related to the higher electron count of $\mathrm{Ru}$ and Os. Despite this encouraging result for a variety of single transformations, activation energies well above $30 \mathrm{kcal} \mathrm{mol}^{-1}$ were calculated, indicating a need for further theoretical investigations. We reasoned that a computational study focusing on Group 8 metal complexes in the oxidation state A $\quad+2$ should help to identify catalyst lead structures for the reduction of $\mathrm{N}_{2}$ by $\mathrm{H}_{2}$. In this study we investigated iron, ruthenium, and osmium complexes of the general type $\mathbf{A}(\mathrm{D}=$ donor group) with various pincer ligands, for the following reasons:

1) We assume that octahedral coordination polyhedra will be the dominating coordination geometry for this type of complex (with $\mathrm{Ru}^{2+}$ as the central atom, for example). Accordingly, the pincer ligand should occupy three of the six coordination sites permanently and thus help to shield the metal center from the formation of-presumably-unreactive dimeric species containing, for example, the M-N-N-M structural motif. The formation of the M$\mathrm{N}-\mathrm{N}-\mathrm{M}$ unit was proven by crystal structure analyses for $\left[\{\mathrm{RuH}(\mathrm{pcp})\}_{2}\left(\mu-\mathrm{N}_{2}\right)\right],{ }^{[13]}\left[\left\{\mathrm{RuH}\left(\mathrm{N}_{2}\right)(\mathrm{pcp})\right\}_{2}\left(\mu-\mathrm{N}_{2}\right)\right](\mathrm{pcp}=$ $\left.1,3-\left(\mathrm{CH}_{2} \mathrm{P} t \mathrm{Bu}_{2}\right)_{2} \mathrm{C}_{6} \mathrm{H}_{4}\right),{ }^{[13]}$ and $\left[\left\{\mathrm{RuH}_{2}\left(\mathrm{~N}_{2}\right)\left(\mathrm{PiPr}_{3}\right)_{2}\right\}_{2}(\mu-\right.$ $\left.\left.\mathrm{N}_{2}\right)\right]^{[14]}$ as well as for $\left[\{\mathrm{RuCp}(\operatorname{dippe})\}_{2}\left(\mu-\mathrm{N}_{2}\right)\right]^{2+}(\mathrm{Cp}=$ cyclopentdiene, $\quad$ dippe $=1,2$-bis(diisopropylphosphanyl)ethane) and $\left[\left\{\mathrm{RuCp}\left(\mathrm{PEt}_{3}\right)\right\}_{2}\left(\mu-\mathrm{N}_{2}\right)\right]^{2+} \cdot{ }^{[15]}$ In practical applications, appropriate shielding preventing dimer formation can be introduced into the model complexes studied here by attaching sterically demanding substituents (R) to the $\mathrm{P}$ centers of the ligand. The decision on which substituent is appropriate is not addressed in this study.

2) Mononuclear ruthenium complexes, such as $\mathbf{1}^{[16]}$ and $\mathbf{2}^{[17]}$ with an ether and a nitrogen donor group, respectively,

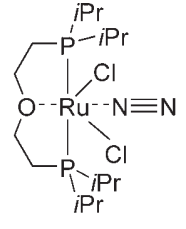

1

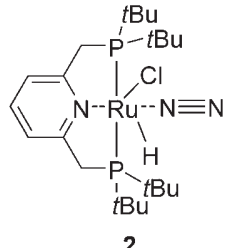

2 in the ligand backbone and each bonding one $\mathrm{N}_{2}$ molecule end-on, had already been shown to be available synthetically and were characterized crystallographically, thus proving that $\mathrm{N}_{2}$ complexes of this kind are accessible. For 1 it was also shown that $\mathrm{N}_{2}$ can be displaced by $\mathrm{H}_{2}$, indicating that dissociation or reassociation of either $\mathrm{H}_{2}$ or $\mathrm{N}_{2}$ should be possible under appropriate conditions.

3) Nonclassical ruthenium complexes such as 3, which among other complexes of this type are currently under investigation by our group, are able to coordinate or dissociate $\mathrm{H}_{2}$ molecules reversibly and also to activate aromatic $\mathrm{C}-\mathrm{H}$ bonds under mild conditions, proving a significant catalytic activity. ${ }^{[18]}$

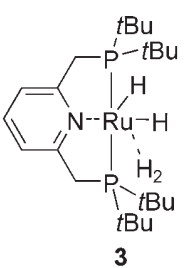

4) Iron and osmium complexes are included in parts of the study to obtain information about their potential catalytic performance (that is, existence of local minima and transition states and relative energies) in one of the crucial steps of nitrogen reduction.

\section{Results and Discussion}

This work is in three parts: 1) calculation of initial transfer of one hydrogen center onto coordinated $\mathrm{N}_{2} ; 2$ ) calculation of complete catalytic cycles for $\mathrm{N}_{2}$ reduction (sometimes with the inclusion of solvent); 3) calculation of local minima and transition states necessary to convert the catalyst precursors into active catalyst species.

Initial hydrogen transfer: As the aim of the study was calculation of complete catalytic cycles for $\mathrm{N}_{2}$ reduction, it was efficient to concentrate on the initial hydrogen transfer as a first part of this computational catalyst screening. As our previous theoretical work ${ }^{[12]}$ in accordance with conventional wisdom had shown that one of the energetically very demanding reaction steps is the initial transfer of a metalbonded hydride center onto coordinated $\mathrm{N}_{2}$, we initiated our study by using hypothetical structures $\mathbf{4}$ and $\mathbf{5}$, which are model complexes derived from catalyst $\mathbf{3}$. We calculated local minima and transition states associated with the initial transfer of one metal-bonded hydride onto coordinated $\mathrm{N}_{2}$. For the bisphosphane ligands with ether groups in the backbone, we then calculated catalytic cycles for $\mathrm{N}_{2}$ reduction. Scheme 1 shows the reaction investigated together with the 


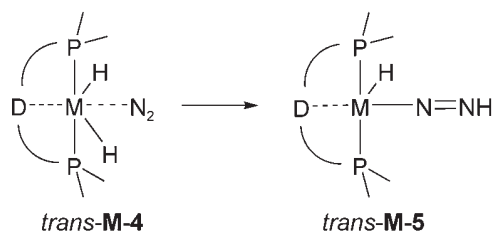

$\mathrm{M}=\mathrm{Fe}, \mathrm{Ru}, \mathrm{Os}$
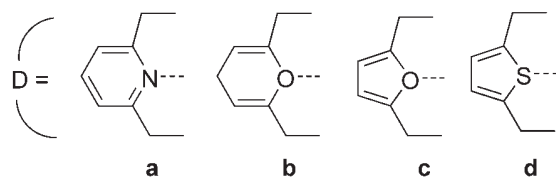

Scheme 1. Computationally investigated reaction of trans-M-4 to transM-5 with a variety of metals and ligand backbones.

ligand backbones used. In this way we hoped to assess the influence of different metals and different donor abilities of groups $\mathrm{D}$ in the ligand backbone.

Ligand backbone a was investigated first. Complex transRu-4a could be identified with $\mathrm{N}_{2}$ both in side-on and in end-on coordination mode, but to our disappointment it was not possible to locate a transition state leading to trans-Ru5 a (Scheme 2a). Similar results were obtained for the corresponding Fe and Os complexes, indicating that trans-M-4a is not a suitable catalyst candidate for $\mathrm{N}_{2}$ reduction when a metal-bonded hydride is to be transferred (Scheme 2a). Alternatively trans- $\mathbf{R u}-4$ a can react with one additional $\mathrm{H}_{2}$ molecule, which approaches the complex from the outer co- a)
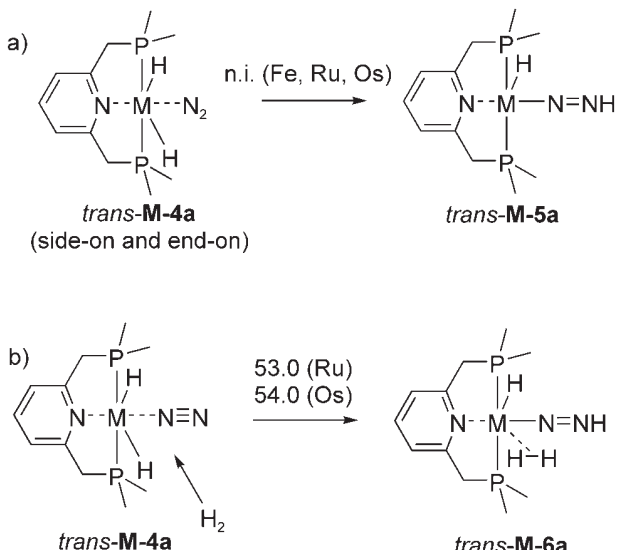

(end-on)
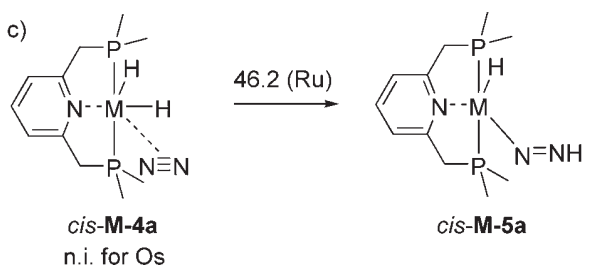

cis-M-5a
Scheme 2. Calculated PNP-M complexes $(\mathrm{M}=\mathrm{Fe}, \mathrm{Ru}, \mathrm{Os})$ involved in initial hydrogen transfer to $\mathrm{N}_{2}$ with activation energies $\Delta E^{\neq}\left(\mathrm{kcalmol}^{-1}\right)$ shown above the reaction arrows. For details, see the text; n.i. $=$ not identified. Structural representations with selected parameters are given in the Supporting Information. ordination sphere by breaking the $\mathrm{H}-\mathrm{H}$ bond and transferring one $\mathrm{H}$ atom to the $\mathrm{N}_{2}$ moiety, while the other forms a nonclassically bonded $\mathrm{H}_{2}$ molecule with the hydride center present at the metal center. In this way complex trans-Ru$\mathbf{6 a}$ is generated (Scheme $2 \mathrm{~b}$ ). The activation energy for this step is $53.0 \mathrm{kcal} \mathrm{mol}^{-1}$. All subsequent reaction steps aiming at the formation of $\mathrm{NH}_{3}$ starting with catalyst trans-Ru-4a would rely on this initial reaction and consequently prohibit practical application. The calculations for the corresponding osmium complexes indicated the activation energy to be similar $\left(54.0 \mathrm{kcal} \mathrm{mol}^{-1}\right)$.

However, using cis-Ru-4a with $\mathrm{N}_{2}$ bonded side-on as the starting complex, generation of a metal-bonded $\mathrm{M}-\mathrm{N}=\mathrm{NH}$ unit is possible. However, the activation energy for this reaction of $46.2 \mathrm{kcal} \mathrm{mol}^{-1}$ indicates the reaction is not possible in practice (Scheme 2c). All computationally derived results for ligand system a are in accord with our repeated experimental attempts to produce $\mathrm{NH}_{3}$ in the presence of $\mathrm{N}_{2}, \mathrm{H}_{2}$, and catalyst precursor $\left[\mathrm{Ru}(\mathrm{H})_{2}\left(\mathrm{H}_{2}\right)(\mathrm{PXP})\right](\mathrm{PXP}=\operatorname{bis}(2,5-$ di-tert-butylphosphanylmethyl)pyridine), in which no formation of $\mathrm{NH}_{3}$ occurred. ${ }^{[19]}$ The corresponding osmium complex cis-Os-4a with $\mathrm{N}_{2}$ bonded side-on in the starting material could not be identified.

In the next step of the study $\gamma$-pyran (ligand backbone $\mathbf{b}$ ) was exchanged for the pyridine ring, as we wanted to introduce a less electron-donating ligand with as little structural change as possible. Such POP-Ru pincer complexes with this ligand are not yet known, to the best of our knowledge. In contrast to the corresponding pyridine complex, the $\gamma$ pyran compound enables the $\mathrm{H}$ transfer from the ruthenium center to the $\mathrm{N}$ atom of the $\mathrm{N}_{2}$ unit, as we identified reactant trans- $\mathbf{R u}-\mathbf{4 b}$, product trans- $\mathbf{R u}-\mathbf{5} \mathbf{b}$, and transition state TS(trans-Ru-4b/5b) (Scheme 3a).

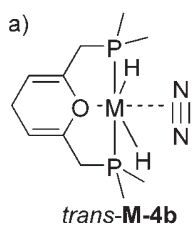

b)
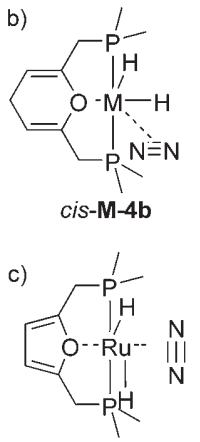

trans-M-4c
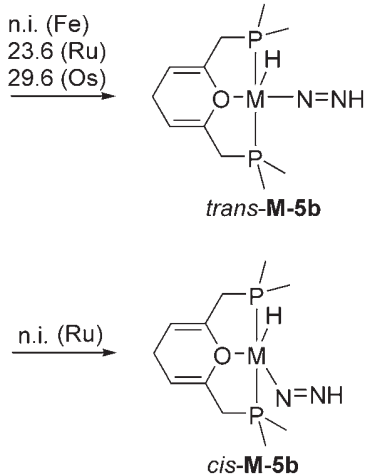

$22.0(\mathrm{Ru})$ 28.5 (Os)

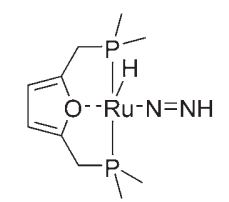

trans-M-5c
Scheme 3. Calculated POP-M complexes $(\mathrm{M}=\mathrm{Fe}, \mathrm{Ru}, \mathrm{Os})$ involved in initial hydrogen transfer to $\mathrm{N}_{2}$ with activation energies $\Delta E^{+}\left(\mathrm{kcal} \mathrm{mol}^{-1}\right)$ shown above the reaction arrows. For details, see the text; n.i. =not identified. Structural representations with selected parameters are given in the Supporting Information. 
To our surprise the activation energy $\Delta E^{\neq}$was fairly low $\left(23.6 \mathrm{kcal} \mathrm{mol}^{-1}\right)$. The corresponding iron complex trans-Fe4b was identified as well as the product trans-Fe-5b, but the transition state $\mathbf{T S}($ trans-Fe-4b/5b) does not exist. The corresponding osmium compounds were identified, but the activation barrier for the reaction from trans-Os-4b to trans-Os5b was significantly higher $\left(\Delta E^{\neq}=29.6 \mathrm{kcal} \mathrm{mol}^{-1}\right.$; Scheme $3 a)$. For the ruthenium complex, calculations to check whether the same reaction would occur if the $\mathrm{N}_{2}$ molecule was coordinated side-on and cis to the $\gamma$-pyran ring showed the starting complex cis-Ru-4b to exist, but no transition state could be identified. This indicates that the reaction is possible only when the $\mathrm{N}_{2}$ molecule is coordinated trans to the $\gamma$-pyran ring. After furan was exchanged for the $\gamma$-pyran ring, trans-Ru-4c, trans-Ru-5c and TS(trans-Ru-4c/ 5c) were also identified, the activation energy being slightly lower than that of the $\gamma$-pyran system $\left(\Delta E^{\neq}=22.0 \mathrm{kcal}\right.$ $\mathrm{mol}^{-1}$; Scheme 3c). Again the corresponding osmium complexes were identified, but yielded a clearly higher activation barrier $\left(\Delta E^{\neq}=28.5 \mathrm{kcal} \mathrm{mol}^{-1}\right)$. Interestingly, with the ether-containing ligand systems the activation energies were similar and slightly above $20 \mathrm{kcal} \mathrm{mol}^{-1}$, whereas although the corresponding osmium complexes were identified, their activation barriers were approximately $6 \mathrm{kcal} \mathrm{mol}^{-1}$ higher. We therefore excluded any osmium compounds from the rest of the study. As the transition state for the $\gamma$-pyran system could not be identified using the corresponding iron complex, we ruled out iron at this point and did no calculations for any further iron complexes.

To check the influence of thioether groups, we did calculations for the corresponding thiophene complexes trans-
Ru-4d and trans-Ru-5d (ligand system d) and found both reactant and product to exist on the hypersurface. However, no transition state was found, indicating this donor not to be suitable for the generation of an active catalyst.

Calculation of catalytic cycles for $\mathbf{N}_{2}$ reduction: The results obtained so far indicate a preference for ruthenium as the metal center rather than iron and osmium, while ligand backbones with ether groups seem to be favored over the stronger nitrogen- or sulfur-donor-containing ligands. We therefore calculated the catalytic cycles for the $\gamma$-pyran and the furan system to find out whether there were any closed catalytic cycles (Scheme 4). We aimed to compare the reaction energies of the two systems to estimate how much these two seemingly alike ligands would influence the different reaction steps; the corresponding energy profiles for the $\gamma$ pyran and the furan system are shown in Figure 1 (they are very similar with one exception, vide infra; the complexes have been renumbered, for clarity). Table 1 contains relative energies of the complexes associated with the reduction cycles.

Summarizing the reaction mechanisms briefly for both the $\gamma$-pyran and the furan system: the $\mathrm{N}_{2}$ reduction starts with the first transfer of a hydride to the coordinated $\mathrm{N}_{2}$ molecule $(\mathbf{I} \rightarrow \mathbf{I I})$. Subsequently a new $\mathrm{H}_{2}$ molecule is coordinated at the metal center (III), which then reacts with the $\mathrm{Ru}-\mathrm{N}=$ $\mathrm{NH}$ moiety. The $\mathrm{H}-\mathrm{H}$ bond is broken and one hydrogen center is transferred to the external nitrogen atom resulting in the formation of a $\mathrm{Ru}=\mathrm{N}-\mathrm{NH}_{2}$ unit, while the other hydrogen atom is bonded to the metal (IV). In principle one of the hydride centers could at this stage react with the $\mathrm{NH}_{2}$
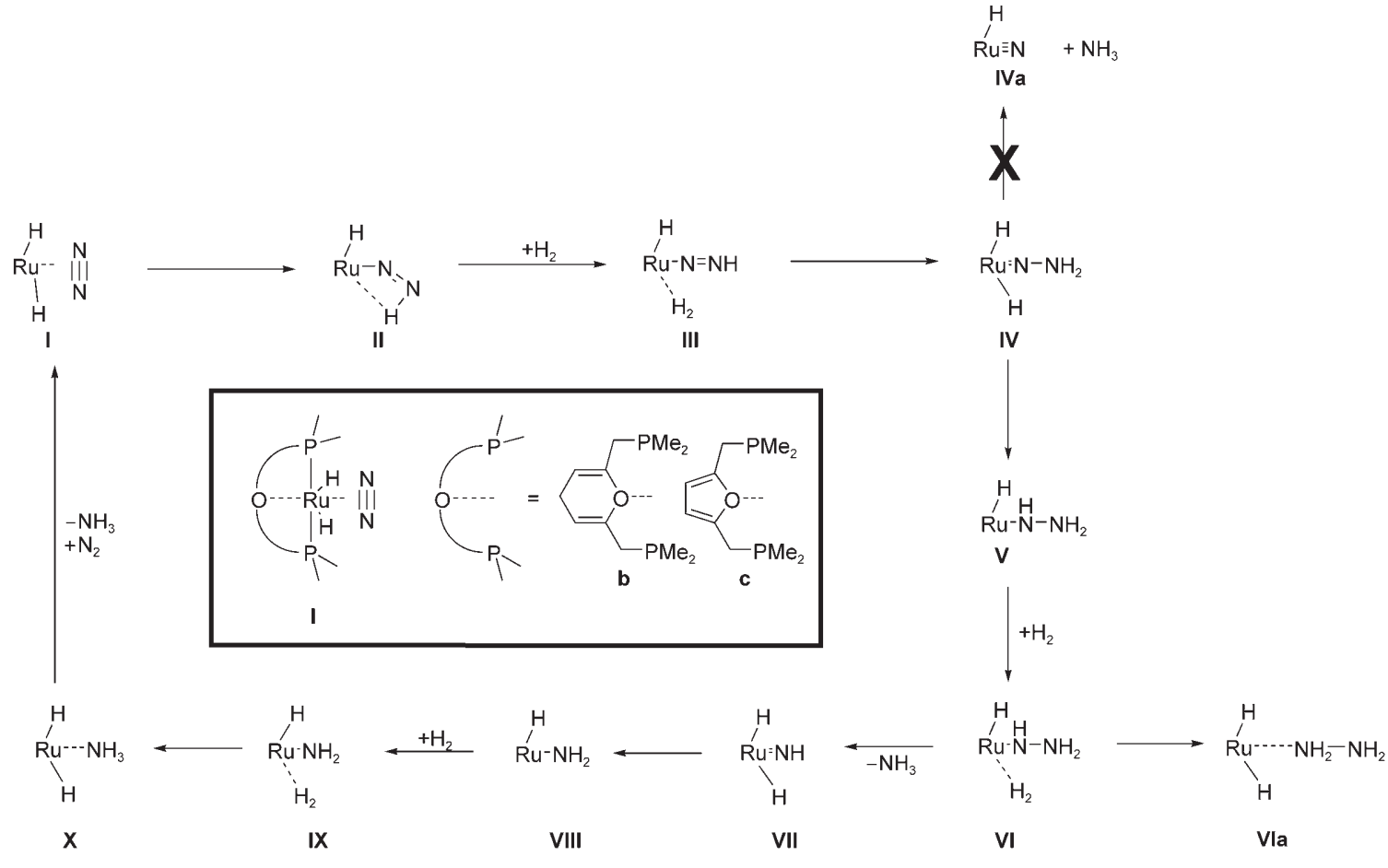

Scheme 4. Calculated catalytic cycle for POP-Ru pincer complexes with ligand backbones $\mathbf{b}$ and $\mathbf{c}$. 


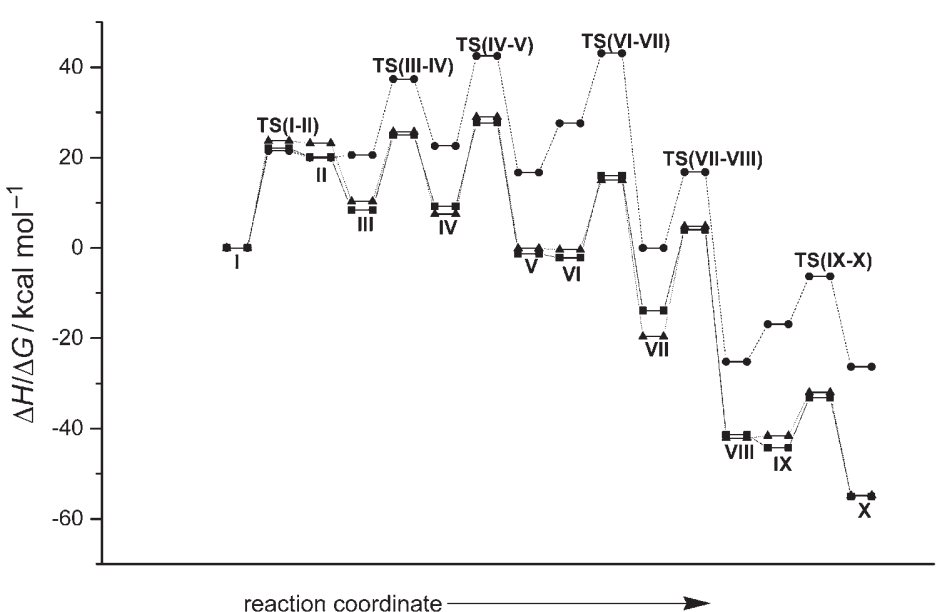

Figure 1. Energy profiles of the main part of the calculated catalytic cycles: gas-phase energies $\Delta E\left(\mathrm{kcal} \mathrm{mol}^{-1}\right)$ of the catalysts with $\Delta$ the $\gamma$ pyran (b) and $\mathbf{a}$ the furan (c) ligand systems; $\bullet$ Gibbs free energies $\Delta G$ $\left(\mathrm{kcal} \mathrm{mol}^{-1}\right)$ of the catalyst with the furan ligand system (c) in toluene as the solvent.

Table 1. Relative energies $\Delta E$ and Gibbs free energies $\Delta G$ (all in kcal $\mathrm{mol}^{-1}$ ) of complexes associated with $\mathrm{N}_{2}$ reduction using ligand systems $\mathbf{b}$ and $\mathbf{c}$ in the gas phase (b, c) and in toluene (c).

\begin{tabular}{lccc}
\hline & $\Delta E(\mathbf{b})$ gas & $\Delta E(\mathbf{c})$ gas & $\Delta G(\mathbf{c})$ toluene \\
\hline I & 0.00 & 0.00 & 0.00 \\
II & 23.2 & 20.1 & 20.0 \\
III & 10.3 & 8.4 & 20.6 \\
IV & 7.5 & 9.2 & 22.6 \\
V & -0.1 & -1.3 & 16.7 \\
VI & -0.4 & -2.2 & 27.6 \\
VII & -19.6 & -13.9 & 0.0 \\
VIII & -42.1 & -43.2 & -25.2 \\
IX & -42.6 & -44.3 & -16.9 \\
X & -54.8 & -55.0 & -26.3 \\
TS(I-II) & 23.7 & 22.1 & 21.6 \\
TS(III-IV) & 25.7 & 25.0 & 37.4 \\
TS(IV-V) & 29.0 & 27.7 & 42.5 \\
TS(VI-VII) & 15.0 & 16.0 & 43.1 \\
TS(VII-VIII) & 4.8 & 4.0 & 16.8 \\
TS(IX-X) & -32.0 & -33.2 & -6.3 \\
TS(VI-VIa) & 10.1 & 9.2 & 36.8 \\
\hline
\end{tabular}

group, forming the first $\mathrm{NH}_{3}$ molecule and the corresponding ruthenium nitride (IVa). Interestingly, although the product could be located on the hypersurface, the transition state does not exist, as repeated attempts to locate it failed. This is a clear contrast to the catalysts containing the trisamidoamine ligand, which we reported earlier. For these complexes we found the corresponding transition state leading the reaction to the metal nitride. This has direct consequences for potential practical applications: here the impossibility of locating a transition state to generate IVa indicates that these types of pincer complexes would not form unreactive nitrides; in other words, in a potential reaction the catalyst would not be consumed.

In an alternative step the hydride center is transferred to the internal nitrogen atom, resulting in the formation of a $\mathrm{Ru}-\mathrm{NH}-\mathrm{NH}_{2}$ unit and creating a vacant coordination site at the metal $(\mathbf{V})$, which is subsequently occupied by $\mathrm{H}_{2}$ (VI). Now the reaction can result in either the formation of the first $\mathrm{NH}_{3}$ molecule of the cycle by breaking the $\mathrm{H}-\mathrm{H}$ bond of the coordinated $\mathrm{H}_{2}$ molecule and transfer of one hydrogen to the $\mathrm{NH}_{2}$ group (VII), or reaction of the hydrogen center with the nitrogen atom of the $\mathrm{NH}$ unit resulting in the formation of a coordinated hydrazine molecule (VIa). Kinetically the latter reaction $\left(\Delta E^{\neq}=10.3\right.$ and $9.9 \mathrm{kcal} \mathrm{mol}^{-1}$ for ligand systems $\mathbf{b}$ and $\mathbf{c}$, respectively) is clearly more favored than the former one $\left(\Delta E^{+*}=15.4\right.$ and $16.3 \mathrm{kcalmol}^{-1}$ for ligand systems $\mathbf{b}$ and $\mathbf{c}$, respectively), but hydrazine formation is endothermic. As the barrier for the reaction of VIa to VI is $23.9 \mathrm{kcal} \mathrm{mol}^{-1}$ for the $\gamma$-pyran complex and $23.0 \mathrm{kcal} \mathrm{mol}^{-1}$ for the furan complex, the hydrazine complexes VIa should both be able to re-enter the cycle. Alternatively, after the formation of $\mathrm{NH}_{3}$ from the reaction of $\mathbf{V I}$ to VII an imido unit is present at the metal center that, by reaction with one of the hydride centers, is converted to an amido unit (VIII). This complex again has a vacant coordination site which is occupied by $\mathrm{H}_{2}(\mathbf{I X})$ and in a final reaction the $\mathrm{H}-\mathrm{H}$ bond is broken, while the second $\mathrm{NH}_{3}$ molecule is created and coordinates to the metal center $(\mathbf{X})$. By dissociation of $\mathrm{NH}_{3}$ and re-association of $\mathrm{N}_{2}$ the cycle can start again (for solvation effects, see below).

Most of the calculated activation barriers for the $\gamma$-pyrancontaining catalyst system are below $20.0 \mathrm{kcal} \mathrm{mol}^{-1}$, suggesting these steps are possible in practice. For the furan system all steps except for the initial $\mathrm{H}$ transfer to $\mathrm{N}_{2}$ (vide supra) are below $20.0 \mathrm{kcal} \mathrm{mol}^{-1}$, indicating this cycle to be preferred over the $\gamma$-pyran catalyst system. The most important difference in activation barriers between the two ligands occurs at the step in which the imido group $(\mathrm{Ru}=\mathrm{NH})$ reacts to form the amido group $\left(\mathrm{Ru}-\mathrm{NH}_{2}\right.$; reaction $\mathrm{VII} \rightarrow$ VIII). In the $\gamma$-pyran system this step requires an activation energy $\Delta E^{+}$of $24.4 \mathrm{kcal} \mathrm{mol}^{-1}$, while in the furan system it needs only $16.6 \mathrm{kcal} \mathrm{mol}^{-1}$. All other steps show much less pronounced differences. ${ }^{[20 a, b]}$

We re-optimized the geometries of the gas-phase structures for the furan-containing catalyst system in the presence of a relatively unpolar solvent (toluene), to investigate whether the inclusion of this reaction medium would alter structures and energies to a significant extent. We found no significant geometric changes in structures. Interestingly, the activation barriers $\Delta G^{\ddagger}$ in solution also do not change significantly relative to the gas-phase barriers. The highest activation barrier in solution was found, as in the gas phase, for the initial hydrogen transfer (reaction $\mathbf{I} \rightarrow \mathbf{I I} ; \Delta G^{\neq}=21.5 \mathrm{kcal}$ $\mathrm{mol}^{-1}$ ). In the gas-phase addition of $\mathrm{H}_{2}$ to II yielding III is practically thermoneutral, with a very small exothermic trend $\left(\Delta G=-0.4 \mathrm{kcal} \mathrm{mol}^{-1}\right)$. In solution the same applies, with the trend reversed $\left(\Delta G=0.6 \mathrm{kcalmol}^{-1}\right)$. Upon addition of $\mathrm{H}_{2}$ in the gas phase, complex $\mathbf{V}$ reacts to $\mathbf{V I}$ in an endothermic reaction $\left(\Delta G=9.8 \mathrm{kcal} \mathrm{mol}^{-1}\right)$, while in solution the Gibbs free energy is raised by $10.9 \mathrm{kcal} \mathrm{mol}^{-1}$. An increase in energy of the same magnitude can be observed upon addition of $\mathrm{H}_{2}$ to VIII yielding $\mathbf{I X}$, as $\Delta G$ for the gas phase increases by $9.3 \mathrm{kcal} \mathrm{mol}^{-1}$ and by $8.3 \mathrm{kcal} \mathrm{mol}^{-1}$ for 
the reaction in solution. Though endothermic, the addition of $\mathrm{H}_{2}$ to these complexes should be possible as the energy increase is not too pronounced. To close the catalytic cycle the $\mathrm{NH}_{3}$ molecule in $\mathbf{X}$ must dissociate from the complex while $\mathrm{N}_{2}$ must be added to it. Transition states could not be located, neither for the dissociation of $\mathrm{NH}_{3}$ from $\mathbf{X}$ nor for the addition of $\mathrm{N}_{2}$, although several attempts were made. Single-point calculations for the dissociation of the $\mathrm{NH}_{3}$ molecule from $\mathbf{X}$ to estimate the energy curve showed a nearly linear increase in energy upon removing $\mathrm{NH}_{3}$ from the complex in $0.1 \AA$ steps up to a distance of $4.150 \AA$ A between the metal and the nitrogen center $(\mathrm{Ru}-\mathrm{N}$ in complex $\quad \mathbf{X}=2.152 \AA)$. The same method for the addition of $\mathrm{N}_{2}$ yielded a nearly linear decrease in energy when $\mathrm{N}_{2}$ approaches the metal complex fragment from a distance of $4 \AA$ A. According to this result either it would not be possible to locate a transition state, or its barrier would be too small to be detected with the methods used here. As the free energy of solvation of ammonia $\left(\Delta G_{\text {solv }}=-6.56 \mathrm{kcal} \mathrm{mol}^{-1}\right)$ indicates that $\mathrm{NH}_{3}$ dissolves much better in toluene than $\mathrm{N}_{2}$ $\left(\Delta G_{\text {solv }}=0.18 \mathrm{kcal} \mathrm{mol}^{-1}\right)$, it is reasonable to assume that the $\mathrm{NH}_{3}$ molecule can dissociate from complex $\mathbf{X}$ and instead the complex fragment coordinates with $\mathrm{N}_{2}$, in this way regenerating I. In fact for the reaction of $\mathbf{X}$ with $\mathrm{N}_{2}$ to $\mathbf{I}$ and $\mathrm{NH}_{3} \Delta G$ in solution amounts to $13.6 \mathrm{kcal} \mathrm{mol}^{-1}$. This is an endothermic step, but the energy increase is small enough to be reached by experimental systems.

Generation of the active catalyst species: The catalytic cycles obtained for the $\gamma$-pyran and furan ligand systems can only be active when it is possible to generate the starting complex I from the corresponding hydrides trans-Ru-4b and trans-Ru-4c. We therefore calculated the local minima and transition states associated with the generation of the active catalyst $\mathbf{I}$ from the starting materials (for comparison we included the otherwise inactive trans-Ru-4a, that is, the pyridine ligand system). In Scheme 5 the corresponding structures and relative energies are shown.

There are two ways in which $\mathbf{I}$ can be generated from the parent metal hydrides. The nonclassically bonded $\mathrm{H}_{2}$ molecule in trans-Ru-4n-0 can dissociate from the complex, generating complex Ru-4n-1 $(n=\mathbf{a}, \mathbf{b}, \mathbf{c})$. Instead of occupying the vacant coordination site with either $\mathrm{N}_{2}$ or solvent, the hydride center trans to the ligand can rearrange to yield the corresponding cis complex Ru-4n-2. The rearrangement requires substantially different amounts of energy for the different ligand systems. With the pyridine-containing ligand system a, the reaction can be accomplished, as the activation energy amounts to $14.4 \mathrm{kcal} \mathrm{mol}^{-1}$. With the $\gamma$-pyran system b, the activation energy is much higher $\left(29.3 \mathrm{kcal} \mathrm{mol}^{-1}\right)$, as it is in the furan system c $\left(27.8 \mathrm{kcal} \mathrm{mol}^{-1}\right)$, indicating that chances of accomplishing this reaction in practice might be low. Repetition of the calculations for ligand system $\mathbf{c}$ in the presence of solvent (toluene) indicated that the barrier is slightly lower $\left(\Delta G^{+}=26.4 \mathrm{kcalmol}^{-1}\right)$. An alternative could be the rearrangement of the $\mathrm{H}_{2}$ unit of trans-Ru-4n-0 forming $\mathbf{R u}-\mathbf{4 n - 3}$, which is formally a $\mathrm{Ru}^{4+}$ complex as the central two hydrogen atoms are singly bonded to the metal, but not to each other. The activation energy required to form Ru-4n-3 calculated for ligand systems a and c, $3.4 \mathrm{kcal} \mathrm{mol}^{-1}$ in both cases, is easily possible to achieve. From this complex an $\mathrm{H}_{2}$ molecule might theoretically form trans to the ligand backbone and dissociate from the complex, but as no transition state for such a reaction was identified it is considered improbable.

It is important with regard to potential practical uses of this type of catalyst that the end-on-bonded isomers Ia are significantly more stable for all the ligand systems $\mathbf{a}, \mathbf{b}$, and c than the corresponding side-on-bonded isomers I. This sta- 
bility pattern is in accord with the experimentally obtained crystal structures of complexes $\mathbf{1}$ and $\mathbf{2}$, in which $\mathrm{N}_{2}$ is bonded end-on. However, according to IRC (intrinsic reaction coordinate) calculations, the calculated reaction can only proceed starting from the complexes with the $\mathrm{N}_{2}$ molecule bonded side-on (I). Though it is the thermodynamically less stable isomer, it is not impossible that $\mathbf{I}$ forms in solution. As a consequence the reaction should generally be possible. From the activation energies associated with the generation of the active catalyst, it is evident that the catalyst backbone of the ether systems should be modified to lower the transition-state energy associated with the rearrangement from Ru-4n-1 to Ru-4n-2. If this issue can be resolved, ruthenium pincer complexes might develop into a catalyst class with promising potential for ammonia synthesis.

\section{Conclusion}

In this work we have shown by means of DFT calculations that POP-Ru pincer complexes can be used to generate computationally derived closed catalytic cycles for the synthesis of $\mathrm{NH}_{3}$ from $\mathrm{N}_{2}$ and $\mathrm{H}_{2}$ with appreciably low activation barriers. To the best of our knowledge these are the lowest activation barriers reported to date for molecular $\mathrm{Ru}^{2+}$-complex-catalyzed reduction of $\mathrm{N}_{2}$ to $\mathrm{NH}_{3}$ with $\mathrm{H}_{2}$. In contrast, PNP pincer ligands (containing pyridine as $\mathrm{N}$ donor) as well as PSP ligands (containing thiophene as $\mathrm{S}$ donor) do not allow $\mathrm{NH}_{3}$ synthesis, as the initial transfer of metal-bonded hydrogen to coordinated $\mathrm{N}_{2}$ is not possible in the way found for the POP ligands. Alternative pathways involving $\mathrm{H}_{2}$ bond metathesis of an additional $\mathrm{H}_{2}$ molecule attacking the complex without bonding to the metal before reaction is possible for PNP-Ru complexes in general. However, practical application might be hindered due to the high activation barriers. Comparison of $\mathrm{POP}-\mathrm{Ru}$ catalyst systems with POP-Os and POP-Fe catalysts hints at less favored (that is, higher) activation barriers or/and at nonexistent local minima and transition states, respectively, in this way clearly favoring POP-Ru catalysts. The inclusion of solvent effects for the furan-containing POP-Ru catalyst indicates Gibbs free activation energies to be very similar to the gasphase activation barriers. To the best of our knowledge this is the first time a POP-Ru pincer complex has been shown to be potentially useful for homogeneously catalyzed $\mathrm{NH}_{3}$ production from $\mathrm{N}_{2}$ and $\mathrm{H}_{2}$. However, issues with the generation of the active catalyst species from the catalyst precursor due to high activation barriers for rearrangement of metal-bonded hydride centers might impede practical realization of the reaction. Further theoretical work to clarify and improve this situation is under way.

\section{Computational Details}

All calculations were carried out using the Gaussian $03^{[21]}$ program series, implemented with the B3 LYP ${ }^{[22]}$ hybrid functional. For nonmetal atoms the TZVP basis set by Ahlrichs et al., as implemented in Gaussian 03, ${ }^{[23]}$ was used, while for the metal atoms a (311111/22111/411/1 (Fe); 311111/ $22111 / 411(\mathrm{Ru}, \mathrm{Os}))$ basis set was used in combination with the Stuttgart/ Köln ECP. ${ }^{[24]}$ All stationary points were checked by frequency calculations to be either minima $(i=0)$ or transition states $(i=1)$, while IRC calculations carried out for most of the identified transition state structures proved that the correct products and reactants were connected by that transition state. Tables with energies, zero-point vibrational corrected energies, enthalpies, and Gibbs free energies ( $T=298 \mathrm{~K}, p=1$ bar $)$ are contained in the Supporting Information, as well as Cartesian coordinates and structural representations of most of the calculated compounds. Calculations (geometry optimization followed by frequency calculation) in the presence of a solvent (toluene, dichloromethane) were carried out using the self-consistent reaction field (SCRF) formalism, as implemented in Gaussian 03 employing the IEF-PCM (integral equation formulation of the polarizable continuum model $)^{[25]}$ together with the united atom topological model for radii. Extra spheres for hydrogen were added for $\mathrm{H}_{2}, \mathrm{NH}_{3}, \mathrm{~N}_{2} \mathrm{H}_{4}$, and all the hydrogen atoms in the complexes present at the $\mathrm{Ru}$ center and at the mono- or dinitrogen moieties in all the reaction steps. During the geometry optimizations and the subsequent frequency calculations, the calculation of dispersion solute-solvent interaction energy, of repulsion solute-solvent interaction energy, and of the cavitation energy was switched off.

\section{Acknowledgements}

Generous allocation of computer time by the Computation and Communication Center of the RWTH Aachen is gratefully acknowledged. We greatly appreciate helpful discussions with Professor B. Mennucci, Pisa (SCRF calculations).

[1] R. Schlögl, Angew. Chem. 2003, 115, 2050-2055; Angew. Chem. Int. Ed. 2003, 42, 2004-2008 and references cited therein.

[2] J. Haggin, Chem. Eng. News 1993, 71, 23-27.

[3] F. Studt, N. Lehnert, B. E. Wiesler, A. Scherer, R. Beckhaus, F. Tuczek, Eur. J. Inorg. Chem. 2006, 291-297.

[4] M. D. Fryzuk, J. B. Love, S. J. Rettig, V. G. Young, Science 1997, 275, 1445-1447.

[5] G. K. B. Clentsmith, V. M. E. Bates, P. B. Hitchcock, F. G. N. Cloke, J. Am. Chem. Soc. 1999, 121, 10444-10445.

[6] R. A. Henderson, J. Chem. Soc. Dalton Trans. 1982, 917-925.

[7] O. Franke, B. E. Wiesler, N. Lehnert, F. Tuczek, Z. Anorg. Allg. Chem. 2002, 628, 2395-2402.

[8] a) J. Chatt, J. R. Dilworth, R. L. Richards, Chem. Rev. 1978, 78, 589-625; b) M. Hidai, Y. Mizobe, Top. Organomet. Chem. Vol. 3 (Ed.: S. Murai), Springer, Berlin, 1999, pp. 227-241; c) M. P. Shaver, M. D. Fryzuk, Adv. Synth. Catal. 2003, 345, 1061-1076; d) M. D. Fryzuk, Chem. Rec. 2003, 3, 2-11; e) C. M. Kozak, P. Mountford, Angew. Chem. 2004, 116, 1206-1209; Angew. Chem. Int. Ed. 2004, 43, 1186-1189; f) H. J. Himmel, M. Reiher, Angew. Chem. 2006, 118, 6412-6437; Angew. Chem. Int. Ed. 2006, 45, 6264-6288; g) F. Studt, F. Tuczek, J. Comput. Chem. 2006, 27, 1278-1291; h) Y. Ohki, M. D. Fryzuk, Angew. Chem. 2007, 119, 3242-3245; Angew. Chem. Int. Ed. 2007, 46, 3180-3183; i) B. A. MacKay, M. D. Fryzuk, Chem. Rev. 2004, 104, 385-401.

[9] a) J. A. Pool, E. Lobkovsky, P. J. Chirik, Nature 2004, 427, 527-530; b) H. Miyachi, Y. Shigeta, K. Hirao, J. Phys. Chem. A 2005, 109, $8800-8808$; c) P. Bobadova-Parvanova, Q. Wang, D. QuinoneroSantiago, K. Morokuma, D. G. Musaev, J. Am. Chem. Soc. 2006, 128, 11391-11403; d) P. Bobadova-Parvanova, Q. Wang, K. Morokuma, D. G. Musaev, Angew. Chem. 2005, 117, 7263-7265; Angew. Chem. Int. Ed. 2005, 44, 7101-7103; e) D. G. Musaev, P. BobadovaParvanova, K. Morokuma, Inorg. Chem. 2007, 46, 2709-2715.

[10] a) D. V. Yandulov, R. R. Schrock, J. Am. Chem. Soc. 2002, 124, 6252-6253; b) D. V. Yandulov, R. R. Schrock, Science 2003, 301, 7678; c) R. R. Schrock, Chem. Commun. 2003, 2389-2391; d) D. V. 
Yandulov, R. R. Schrock, A. L. Rheingold, C. Ceccarelli, W. M. Davis, Inorg. Chem. 2003, 42, 796-813; e) V. Ritleng, D. V. Yandulov, W. W. Weare, R. R. Schrock, A. S. Hock, W. M. Davis, J. Am. Chem. Soc. 2004, 126, 6150-6163; f) D. V. Yandulov, R. R. Schrock, Inorg. Chem. 2005, 44, 1103-1117; g) R. R. Schrock, Acc. Chem. Res. 2005, 38, 955-962.

[11] a) F. Studt, F. Tuczek, Angew. Chem. 2005, 117, 5783-5787; Angew. Chem. Int. Ed. 2005, 44, 5639-5642; b) B. Le Guennic, B. Kirchner, M. Reiher, Chem. Eur. J. 2005, 11, 7448-7460; c) M. Reiher, B. Le Guennic, B. Kirchner, Inorg. Chem. 2005, 44, 9640-9642.

[12] M. Hölscher, W. Leitner, Eur. J. Inorg. Chem. 2006, 4407-4417.

[13] D. G. Gusev, F. M. Dolgushin, M. Y. Antipin, Organometallics 2000, 19, 3429-3434.

[14] K. Abdur-Rashid, D. G. Gusev, A. J. Lough, R. H. Morris, Organometallics 2000, 19, 1652-1660.

[15] H. Aneetha, M. Jimenez-Tenorio, M. C. Puerta, P. Valerga, K. Mereiter, Organometallics 2002, 21, 628-635.

[16] Q. Major, A. J. Lough, D. G. Gusev, Organometallics 2005, 24, 2492-2501.

[17] J. Zhang, M. Gandelman, L. J. W. Shimon, H. Rozenberg, D. Milstein, Organometallics 2004, 23, 4026-4033.

[18] a) M. H. G. Prechtl, M. Hölscher, Y. Ben-David, N. Theyssen, R. Loschen, D. Milstein, W. Leitner, Angew. Chem. 2007, 119, 2319-2322; Angew. Chem. Int. Ed. 2007, 46, 2269-2272; b) M. H. G. Prechtl, Y. Ben-David, D. Giunta, S. Busch, Y. Taniguchi, W. Wisniewski, H. Görls, R. J. Mynott, N. Theyssen, D. Milstein, W. Leitner, Chem. Eur. J. 2007, 13, 1539-1546; c) D. Giunta, M. Hölscher, C. W. Lehmann, R. Mynott, C. Wirtz, W. Leitner, Adv. Synth. Catal. 2003, 345, $1139-1145$.

[19] With DF calculations for $\left[\mathrm{Ru}(\mathrm{H})_{2}\left(\mathrm{H}_{2}\right)(\mathrm{PXP})\right](\mathrm{PXP}=$ bis(2,5-di-tertbutyl-phosphanylmethyl)pyridine] as the catalyst we found the dissociation of the $\mathrm{H}_{2}$ molecule from each of two complexes and subsequent dimerization through one linear oriented $\mathrm{N}_{2}$ molecule yielding $\left[\mathrm{Ru}(\mathrm{H})_{2}(\mathrm{PXP})-\mathrm{N}=\mathrm{N}-\mathrm{Ru}(\mathrm{H})_{2}(\mathrm{PXP})\right]$ to be thermodynamically possible. Experimentally we observed the formation of clusters of an as-yet unknown structure upon pressurizing a toluene solution of $\left[\mathrm{Ru}(\mathrm{H})_{2}\left(\mathrm{H}_{2}\right)(\mathrm{PXP})\right]$ with $\mathrm{N}_{2}$.

[20] a) It is interesting that for complex trans-Ru-4a (that is, a pyridine ligand system), which is not capable of performing the initial hydrogen transfer to the coordinated $\mathrm{N}_{2}$ molecule, a catalytic cycle that is otherwise the same can be calculated as for the $\gamma$-pyran and the furan system with slightly to significantly higher activation barriers in most cases. Moreover, there is an important difference in this cycle: the formation of the undesired metal nitride is possible, indicating that for this class of complexes and for the desired reaction nitrogen ligands seem to be disfavored when one tries to avoid ni- tride formation; b) Comparisons of the complex structures with ligand systems $\mathbf{a}, \mathbf{b}$, and $\mathbf{c}$ for the initial hydrogen transfer to coordinated $\mathrm{N}_{2}$ (and also for other steps of the cycle) make it immediately clear that the distance between the ligand donor element $(\mathrm{N}, \mathrm{O})$ and the metal center must have implications for the bonding between donor and metal (see the Supporting Information for structures). Also, the furan ring of ligand system $\mathbf{c}$, in contrast to the $\gamma$-pyran ring of ligand system $\mathbf{b}$, shows a pronounced ability to rotate away from or toward the metal center, depending on the electronic situation at the metal. A detailed analysis of the structures and the chemical bonding in these complexes will be reported elsewhere.

[21] Gaussian 03, Revision B.03, M. J. Frisch, G. W. Trucks, H. B. Schlegel, G. E. Scuseria, M. A. Robb, J. R. Cheeseman, J. A. Montgomery, Jr., T. Vreven, K. N. Kudin, J. C. Burant, J. M. Millam, S. S. Iyengar, J. Tomasi, V. Barone, B. Mennucci, M. Cossi, G. Scalmani, N. Rega, G. A. Petersson, H. Nakatsuji, M. Hada, M. Ehara, K. Toyota, R. Fukuda, J. Hasegawa, M. Ishida, T. Nakajima, Y. Honda, O. Kitao, H. Nakai, M. Klene, X. Li, J. E. Knox, H. P. Hratchian, J. B. Cross, V. Bakken, C. Adamo, J. Jaramillo, R. Gomperts, R. E. Stratmann, O. Yazyev, A. J. Austin, R. Cammi, C. Pomelli, J. W. Ochterski, P. Y. Ayala, K. Morokuma, G. A. Voth, P. Salvador, J. J. Dannenberg, V. G. Zakrzewski, S. Dapprich, A. D. Daniels, M. C. Strain, O. Farkas, D. K. Malick, A. D. Rabuck, K. Raghavachari, J. B. Foresman, J. V. Ortiz, Q. Cui, A. G. Baboul, S. Clifford, J. Cioslowski, B. B. Stefanov, G. Liu, A. Liashenko, P. Piskorz, I. Komaromi, R. L. Martin, D. J. Fox, T. Keith, M. A. Al-Laham, C. Y. Peng, A. Nanayakkara, M. Challacombe, P. M. W. Gill, B. Johnson, W. Chen, M. W. Wong, C. Gonzalez, J. A. Pople, Gaussian, Inc., Wallingford CT, 2004.

[22] a) A. D. Becke, J. Chem. Phys. 1993, 98, 5648-5652; b) C. Lee, W. Yang, R. G. Parr, Phys. Rev. B 1988, 37, 785-789; c) S. H. Vosko, L. Wilk, M. Nusair, Can. J. Phys. 1980, 58, 1200; d) P. J. Stephens, F. J. Delvin, C. F. Chabalowski, M. J. Frisch, J. Phys. Chem. 1994, 98, $11623-11627$.

[23] a) A. Schäfer, H. Horn, R. Ahlrichs, J. Chem. Phys. 1992, 97, 25712577; b) A. Schäfer, C. Huber, R. Ahlrichs, J. Chem. Phys. 1994, 100, 5829-5835.

[24] D. Andrae, U. Haessermann, M. Dolg, H. Stoll, H. Preuss, Theor. Chim. Acta 1990, 77, 123-141; The basis sets are denoted "Stuttgart RSC 1997" sets and were obtained from the Gaussian Basis Set Order Form at http://www.emsl.pnl.gov/forms/basisform.html (see the Supporting Information).

[25] J. Tomasi, B. Mennucci, R. Cammi, Chem. Rev. 2005, 105, 29993094.

Received: February 20, 2007 Published online: May 22, 2007 